\title{
Antecedentes históricos de la sociología del conocimiento
}

\author{
Julian Morales Navarro
}

\section{Lo irracional, fenómeno básico de la Sociognoseología}

Es de suma importancia el enfrentarse con un problema que se revela a todas las luces como la prehistoria de la Sociognoseología. Y digo prehistoria no en cuanto tal, ya que la Sociología del Conocimiento nos ha aparecido en Mannheim sumamente debilitada en sus principios teniendo en cuenta el poco período de observación con el que contó, sino que esta prehistoria la debemos comprender en el sentido siguiente: a lo largo de toda la evolución histórica de sistemas filosóficos se puede apreciar en ellos la existencia de un elemento desconocido, incontrolable y que sin embargo no es sino el motor, la chispa necesaria para poner en marcha el sistema (materia prima, noumeno, etc.)

¿Nuestro conocer racional es irracional? Podría haberse suprimido la interrogación, me parecía bastante atrevido, aunque en la explicación de este enunciado se ha de correr el riesgo de contestar positivamente. No pocos ante dicho aserto se pondrían en trance filosófico, y no en cuanto sientan curiosidad ante lo dicho sino porque tienen una concepción excesivamente rigorista del conocer en el sentido de considerarlo desgajado de una persona que vive un existir muy concreto y sumamente condicionado. Puede decirse que lo racional es irracional y viceversa, en el sentido de que nuestro conocimiento necesita ser incorporado a la persona y a su concreto vivir; es decir, considerar el conocer no como acto aislado sino como actitud.

Es un problema, el del irracionalismo, importante y de gran actualidad, son expresivas las palabras de K. Popper en su obra "La ciudad abierta y sus enemigos" con las que J.M. Alejandro abre su artículo "Gnoseología de lo irracional": "El conflicto entre el racionalismo y el irracionalismo se ha convertido en el problema intelectual más importante de nuestro tiempo".' Por consiguiente no tomemos lo irracional en un sentido peyorativo sino como esencia inicial de muchos sistemas filosóficos, como una dimensión del sujeto que conoce.

Antes de dar paso al análisis más detallado de este hecho en los autores que podemos considerar como los inmediatos antecesores de la Sociognoseología, es necesario exponer una breve consideración sobre el problema de las certezas libres cuyo claro fundamento lo tienen en el hecho del irracionalismo.

En general podemos definir la certeza como la adhesión firme de la mente ante un

(1) ALEJANDRO, J.: Gnoseología de to irracional. Pensamiento. Vol. 23 (1967). pág. 437. 
enunciable evidente. Muchas son las clases o grupos de certezas pero en todas prevalece un denominador común: firmeza o seguridad. Seguridad de la mente, la cual no es puro entendimiento y voluntad en la persona que conoce, considerar la certeza como una actitud total de la persona. Lo que mayor problema nos plantea es la evidencia del enunciable o la proposición, pues qué hacemos entonces ante las certezas de fe, en las cuales se da una cierta evidencia pero no en el hecho en sí, sino en el trasmisor de la proposición. Así pues, la certeza la hemos de entender analógicamente y no como acto del entendimiento sino como actitud de la persona. Problema éste real, dificil y complejo en la libertad de las certezas de fe.

La evidencia como raiz de la certeza y la naturaleza necesaria del entendimiento parecen crear una dualidad indestructible: evidencia-necesidad, necesidad-certeza. Y el problema queda así ¿Da lugar la evidencia a la entrada de la libertad en el campo de la certeza? ¿Deja la evidencia la posibilidad de una intervención inmediata de la voluntad en el acto de certeza?

Para la solución de este problema partimos de dos series de hechos:

a) De orden psicológico: nuestro apetito como principio motor hacia lo bueno. Si el apetito nos lleva a un bien conforme con la naturaleza racional se llama voluntad, en la cual distinguimos dos series de actos: -Elícitos: que proceden de la misma voluntad como causa eficiente e inmediata.

-Imperados: procedentes de otra potencia pero bajo el imperio de la voluntad.

b) De orden gnoseológico: el orden de certeza en nuestros juicios no es el mismo en todos. La firmeza del asentimiento cierto es diversa en los juicios, pues la evidencia no es univoca y en unos juicios determina imperativamente al entendimiento pero en otros se deja un resquicio mental a un posible error. Este último punto es el que nos interesa, pues, si los motivos presentados al entendimiento no son gnoseológicamente suficientes, la firmeza dependerá en buena parte de la voluntad.

$Y$ toda esta introducción no pretende destronar la razón sino hacer ver la no justificación racional de bastantes realidades.

Muy interesante son unas líneas del Dr. Rabade de su obra "Verdad, conocimiento y ser", en las que analiza las causas del irracionalismo:

"Una primera puede ser la distancia noética que impida el grado de presencialidad mínima del objeto a la potencia, con lo que la relación cognoscitiva quedaría imposibilitada... Más importante es la irracionalidad debida a la desproporción entre la facultad cognoscitiva y el objeto...

N. Hartmann señala otra tercera causa de la irracionalidad aparentemente paradojica: la excesiva proximidad entre el objeto y la facultad cognoscitiva. Sin embargo la paradoja desaparece para quien considere que el conocimiento es una realidad que descansa sobre una estructura, salvo dentro de ideologías idealistas, exige la distinción y separación necesaria entre ambos polos de la relación, para que puede mediar entre ellos una relación sujeto-objeto. Ahora bien, si la proximidad del objeto a la potencia es tal que implique la identidad total, se hace inviable la relación a la que acabamos de referimos. Acaso aquí se encuentre una de las mayores objeciones que se pueden presentar psicológicamente y gnoseológicamente contra la reflexión completa, al menos tal como 
nos lo exponen algunos de sus defensores". 2

Posteriormente continúa el autor exponiendo las diversas formas filosóficas a las que le es connatural el irracionalismo. En primer lugar las filosóficas míticas, en las que más que convencer pretenden aclarar, insinuar, provocar una actitud vital. Los teologismos extremos, construcciones filosóficas sobre una apriorística admisión de un Dios sumamente poderoso. El voluntarismo metafísico, en el que hay un campo totalmente subordinado a una voluntad divina lógica y ontológicamente incontrolable.

Realizada esta breve introducción, se expone a continuación el hecho de lo irracional en los autores más significativos. Irracionalismo que en unos será apetitivo, el entendimiento se persuade de su impotencia en un campo determinado, y en otros más bien perceptivo en cuanto es algo íntimo mediante lo cual entramos en contacto con un mundo de indole superior a los planos alcanzados racionalmente.

\section{Elemento incontrolable en Kant}

a) Exposición kantiana: unas ideas solamente para introducirnos en los presupuestos fundamentales del sistema kantiano, que es un continuo equilibrar, compaginar, coordinar racionalismo y empirismo, procurando adoptar lo positivo de ambos para formular sus juicios, base esencial del sistema:

-En el racionalismo se dan juicios analíticos a priori, que aún siendo universales y necesarios, no obstante son tautológicos.

-En el empirismo se dan juicios analíticos sintéticos a posteriori, que aún siendo particulares y contingentes, sin embargo son extensivos.

$Y$ así Kant extrae por una parte el apriorismo del racionalismo que le permite a sus juicios el ser universales y necesarios; y por otra parte del empirismo el ser sintéticos, lo cual les permite ser extensivos.

Hasta Kant todo estaba polarizado en una relación dual sujeto-objeto, en la que el objeto tenia un influjo extremadamente preminente sobre el sujeto, el cual estaba dentro de la pasividad, quedaba reducido casi a mero receptáculo. $Y$ la tarea que esencializa la postura kantiana, es dar la vuelta al planteamiento a fin de que el influjo casi exclusivo le corresponda al sujeto. Y se dice casi exclusivo en cuanto que el objeto no lo anuló sino que lo relegó exclusivamente a un plano remotísimo. En éste cambio de orientación debemos decir que Kant acertó pero exageró.

b) Raiz del criticismo kantiano: El "yo pienso" cartesiano ha quedado reinterpretado y plasmado en la Crítica de la Razón Pura. Kant inicia su estudio a partir de este principio, pero nos podemos preguntar: ¿en qué queda esencialmente el yo pienso de Kant? Según el planteamiento de Kant, el entendimiento no intuye, no choca con el objeto, sino que conoce en virtud de su autointelección, de una reflexión sobre sí mismo mediante sus operaciones internas.

La operación mediante la cual el entendimiento conoce, queda integrada por los juicios sintéticos a priori, en los que se unifica un apriori con un elemento desor-

(2) RABADE, S.: Verdad, conocimiento y ser. Ed. Gredos. Madrid, 1965, págs. 186-187. 
ganizado material, al cual esencializa dándole sentido. $\mathrm{Y}$ ambas partes son condición esencial para la existencia de cualquier conocimiento; mediante esta síntesis tenemos el módulo para el conocer científico. Científico, en cuanto a él se acomodan todas las ciencias físico-matemáticas. Lo problemático surge en el campo de la metafísica, en el que al no darse ese elemento material no hay posibilidad de atribuirle el carácter de verdadera ciencia. Con esto el problema queda planteado, Kant en primer lugar sólo trata del conocimiento científico, y en segundo lugar trata de buscar cómo es posible la ciencia, y así intentar ver las posibilidades de la metafísica como ciencia.

Como su presupuesto básico son los juicios sintéticos a priori, todo consiste en ver su posibilidad de existencia a nivel de la sensibilidad (Matemática), entendimiento (Física) y razón (Metafísica).

Y así nuestra pregunta inmediata será ¿por qué Kant al salvar la sensibilidad salva la matemática?: la Matemática no nos da cosas sino la cantidad abstraida de las cosas, y la cantidad, según Kant sólo es perceptible por la sensibilidad.

La física mira a la cosa, a la naturaleza, supuesta la Matemătica; así, si logro hacer una sintesis a priori que me lleve al conocimiento de la cosa, salvo la Física. Y por tanto si no hay posibilidad de realizar esa síntesis a nivel de la razón, no salvo la Metafísica.

Continuando con este esquema-síntesis de Kant, la próxima interrogación ha de ser: ¿cuáles son esas dos partes que podemos sintetizar a nivel de sensibilidad y entendimiento, y no es posible sintetizar en la razón?

A nivel de la Estética tenemos: un elemento que viene desorganizado y nos aparece incontrolable, pero es real, perteneciente al campo de la sensibilidad empírica; imposible de expresar dado su carácter amorfo. Elemento que queda esclarecido mediante la adhesión de las formas de espacio y tiempo, pertenecientes al apriori de la sensibilidad pura. Sintesis mediante la cual aparece el fenómeno.

En el campo del entendimiento, el elemento inicial material es el fenómeno que nos lo pasa la sensibilidad; al cual se le insertan los a priori del entendimiento. Dado así como resultado de esta síntesis el conocimiento de las cosas.

Por fin llegamos al campo problemático, al de la razón. A nivel de la sensibilidad y entendimiento se posibilita la síntesis en virtud del elemento exterior que penetra a partir de la sensibilidad. Pero hay tres ideas en el hombre: Dios, alma y cosmos; con imposibilidad de penetrar por la sensibilidad, con lo que se me imposibilita el tener un concepto en mi entendimiento.

c) Irracionalismo en Kant. Irracionalismo como necesidad gnoseológica de la persona humana en cuanto supuesto cognoscente, fuerzas que aún posibilitándonos gnoseológicamente, sin embargo nos es imposible controlarlas racionalmente.

Irracionalismo que debemos considerarlo como una dimensión de nuestra cultura y de todo el existir histórico. Esta idea aparece expuesta por el Dr. Rabades:

"Sobre todo desde Kant hasta nuestros días pocos son los sistemas o los pensadores en cuyo bagaje filosófico y hasta terminológico no nos encontramos con conceptos o expresiones en las que se patentiza esta presencia de lo irracional en su pensamiento, llámese "contenido residual", "ignotumx", "absurdo", o como se quiera. Sin embargo no estamos ante novedad alguna de la filosofia moderna, 
a no ser en la expresión y también, sin duda en la mayor vigencia que lo irracional adquiere en las filosofias postkantianas. El problema de lo irracional es tan viejo como la filosofía o, para ser más exactos, más viejo que las filosofías, ya que la filosofía, por lo menos la europea, nace como una racionalización de determinados contenidos míticos o religiosos, aceptados al margen de todo intento de estructura racional". 3

Y según el planteamiento kantiano no hay más conocimiento racional que el que aparezca a nivel de la sensibilidad y del entendimiento. $Y$ todo elemento que no caiga en uno y otro campo podemos llamarlo irracional, en cuanto incontrolable, así tenemos el noúmeno, anterior a la sensibilidad y que nos aparece desorganizado. Inmediatamente después del entendimiento tenemos a Dios, alma y cosmos, como elementos que caen fuera de nuestro control racional. Ambos extremos que aparecen como incontrolables, los puedo pensar, pero no conocer y por tanto imposible de objetivar.

Kant respecto de la cosa en sí, la ve como irracional en cuanto que lo pienso pero no lo conozco. Igual pasa en Aristóteles respecto de la materia prima, la necesita para poner en marcha su sistema pero para él aparece incontrolable, en cuanto considera imposible expresar en qué consiste.

\section{Nietzsche y la evolución de poder}

En la introducción general a este apartado ha quedado consignada la línea maestra o los pilares fundamentales del hecho de lo irracional.

Ahora pretendemos ver los posibles brotes o líneas de fuerza irracional en la doctrina de Nietzsche, para ello pretendemos analizar los puntos claves de sus sistema filosófico, a fin de descubrir el matiz tras del cual vamos.

Hay en Nietzsche una total radicalización u oposición a todo lo que sea estructuración o sistematización. Concibe el problema filosófico como algo vital, dinámico y por consiguiente difícil de encuadrarlo en unos compartimentos perfectamente delimitados; en él ni hay, ni quiso tener un sistema: "Yo pongo en mis obras toda mi vida y apenas concibo que pueda ser un problema puramente intelectual". Ciertamente son significativas estas palabras por dos motivos:.

-En primer lugar, porque se manifiesta en clara discrepancia con todo lo que suene a estructuración, a estatismo.

-Y en segundo lugar porque baja a la razón de ese palmarés en el que está colocada, dándole más posibilidades, o tratando de armonizarla con ese elemento vitalista, incontrolable racionalmente, pero de inmensa riqueza gnoseológica.

Por consiguiente, adopta una postura tremendamente volutarista y vitalista, con unas matizaciones abiertamente caóticas, y hasta cierto punto pesimistas y desesperanzadoras. Su concepción no es una filosofía, si por ella entendemos pura actividad discursiva, sino más bien un mensaje vital.

(3) RABADE, S.: O.C. pág. 185. 
Como línea directriz de su mensaje, pone la voluntad de poder, y con ella irá a operar una transmutación de todos los valores. Es por esto, por lo que criticó energicamente la cultura superficial, cristiana, burguesa, materializada, masiva de su época.

$Y$ al ser una obsesión la vida, delcara una guerra abierta contra toda moral, en cuanto mata esa vida, así afirmaba que es necesario colgar a los moralistas, pues mientras hablan de felicidad y de virtud no logran ganar para la filosofía sino a unas cuantas viejas. La vida en Nietzsche queda esencializada como ansia de poder, como voluntad de dominio. Esta vida queda convertida en absoluto, explicativa de toda posible creencia; vida con unas fronteras abiertas que nos lleva a construir el superhombre pues lo creía necesario para el desarrollo de la vida.

Vida entendida como voluntad de poder, no voluntad en cuanto facultad del alma sino como conjunto de la vida psicológica, como complejidad de una serie de posibilidades, de sensaciones, emociones, no es la voluntad sino su factor predominante. Así queda degradado al máximo el campo de la libertad, habiendo sido definida por un someter, un dominar a los demás. El movimiento de la vida es la acumulación de fuerzas, con lo que la vida llega al grado máximo de instrumentalización, siendo su factor determinante no la felicidad o el amor, sino la victoria sobre los demás.

Ciertamente sí, después de este inicial esquema, nos detenemos para reflexionar sobre esta postura, no podemos menos que calificar de irracional, vitalista, existencialista la postura de Nietzsche Claro que no un irracionalismo suavemente gnoseológico, sino radical en sus inicios, desarrollo y consecuencias. No hay en él más que un sentir cognoscitivo practicista, no hay más criterio del conocer que el sentimiento del aumento de poder.

Lo único profetizable es la aparición del superhombre, poniendo la voluntad como motor y fuerza del universo. Siguiendo este esquema existencializante y voluntarizado, debemos afrontar la realidad Nietzsche como fundación de una filosofía de los valores. Ahora bien, es una filosofía de los valores egocéntricos al quedar referida a la voluntad de poder, pues toda valoración ha de estar referida a la voluntad de poder. Afirma que actualmente hay un esquema miserable y degenerado de valores, formulado e institucionalizado por un grupo deformado y degenerado, los cristianos, valores que hay que intentar destruir y derrocar para liberar al hombre e interiorizarlo al máximo sin más referencia transcendente que su propio triunfo.

Examinando su plano gnoseológico, vemos que no tiene sentido en su planteamiento lógica alguna. Todo es relativismo, perspectivismo, no hay ni verdad ni mentira. Si niega por tanto todo lo que pueda haber de estabilidad lógica en las cosas. Es más, incluso en los primeros principios se enclaustra dentro del máximo grado de subjetivismo, y la única realidad que nos insinúan es manifestarnos nuestra impotencia de que no podemos pensar de otra forma.

No hay ni sujeto ni objeto, ni sustancia ni accidente, todo queda reducido a pura expresión del lenguaje, son puras palabras. Por consiguiente en dos términos podemos concretar este planteamiento: escepticismo y relativismo, o mejor relativismo que llevado a sus últimos extremos nos proyecta a un escepticismo. El papel de la inteligencia queda caracterizado como creación de ilusiones útiles, luego no hay que buscar la verdad por sí misma, sino por su matiz pragmático-utilitarista.

Como conclusión a este análisis se puede afirmar que todo está planteado hacia un 
horizonte que para él es decisivo, es su única y más íntima finalidad: la aparición del superhombre. La grave dificultad es su definición o descripción al no haber aparecido aún. La única descripción posible se puede hacer viendo cómo evoluciona la vida y así conjeturar hasta donde pueda llegar el superhombre. La voluntad de poder se desplegará al máximo, tendrá una naturaleza vigorosa, una sobreabundancia de vida. $\mathrm{El}$ mismo creará sus valores, todos los valores, sin más norma disciplinar, sin más ley que su voluntad, será legislador, dueño y tirano de la multitud. Lo grave es cómo sintetizar eternidad y tiempo, su postura es de que todo va y viene, todo vuelve, y el ciclo de la existencia comienza nuevamente. No hay creación posible, la materia es eterna y cl tiempo es infinito.

Por tanto, todos han de perseguir como realización inmediata adaptarse al medio, adaptación que es acción vital, así el conocimiento queda instrumentalizado. Todo este proceso tiene un aspecto teleológico que en general es el hombre, más en concreto la aparición del superhombre. Nietzsche se siente sólo en el mundo, soledad que le lleva a conservar dentro de sí una mirada penetrante e interpeladora, capaz de cambiar tanto la historia como los componentes de la misma, los hombres.

Se aprecian en Nietzsche claramente tres momentos bien definidos:

-En sus inicios todo lo cifra en una lucha desesperada por un nuevo ideal de cultura, el ideal del hombre estético y heróico.

-En un segundo momento se declara abierto enemigo de toda metafísica, elogiando tanto el conocimiento frío como el espíritu libre.

- Por último aparece en su trayectoria, la voluntad de poder que será el camino hacia los nuevos valores.

Todo está por tanto, en la capacidad de adaptarse a este mundo en el que vivimos. Y el conocimiento será el resultado de la necesidad vital de adaptarse, con lo que la vida queda convertida en la fuerza creadora del conocimiento.

\section{El irracionalismo de Henri Bergson}

a) La intuición bergsoniana. Estudio el punto clave, resumen y médula del irracionalismo bergsoniano. Pues bien, dentro de su filosofia hemos de situar la intuición simultáneamente como conclusión última y como punto de partida. Como punto de partida porque toda la filosofía de Bergson es sistemáticamente intuitiva. Y como última conclusión, pues la intuición no es más que la consecuencia positiva y necesaria de la crítica ontológica-gnoseológica que, incluso cronológicamente, es el comienzo filosófico de Bergson. Veamos de una forma esquemática cual es el camino de llegada a la intuición.

El primer paso es una nueva concepción de la realidad, que es ella intuitiva, pudiendo centrarse en las siguientes afirmaciones: "La realidad no es estática, consiste en devenir". "La medida que puede enmarcar a esta realidad, no puede ser el tiempo físico, que en ningún modo coincide con el tiempo real".

Después de afirmar que el tiempo capaz de medir al "etre se faisant", es donde debemos situar la crítica, dura crítica, a la que Bergson somete el entendimiento y que puede quedar resumida en sus puntos más significativos: "El entendimiento es apriorístico en su conocer, se limita a desmenuzar la realidad encasillándola en sus 
esquemas", "El entendimiento, con lo que este concepto tiene implícito de estaticidad, está radical y absolutamente imposibilitado de percibir la realidad tal y como ella es".

Se puede pensar que estos dos calificativos, "apriorístico" y "estaticidad", reflejan con bastante exactitud las trabas que Bergson pone al conocer verdadero del entendimiento. Hasta aquí los postulados básicos de los que Bergson deduce la necesidad de otro medio, la intuición como modo imprescindible del conocer cierto.

Efectivamente, el vitalismo incluido en el ser de Bergson, el concepto nuevo de "durée", el élan vital, que Bergson propone como esencia íntima y última de toda la realidad, no puede ser aprehendido por el entendimiento apriorista y estático. Cuando poseemos la verdadera realidad es cuando sintonizamos con el ser del devenir. Es necesaria una asimilación temporal y de contenido, con la realidad misma. Es entonces cuando los conceptos dejan de ser tales para empezar a ser intuición. "Bajamos al interior de nosotros mismos - dice Bergson- más profundo será el empuje que nos volverá a la superficie". Es ésta una de las más vivas descripciones que Bergson hace de su intuición. Nuestro contacto con la realidad, debe ir precedido de un descenso a la realidad. Un descenso que consiste en la adaptación de nuestro "ego cognoscens" a la realidad consistente en devenir. En realidad, la intuición bergsoniana consiste en un cambio de sistema: el conocer cierto no se produce cuando encasillamos la realidad, sino cuando nosotros mismos nos encasillamos con la realidad, cuando en alguna manera nos identificamos con el objeto conocido. $Y$ que esto no nos haga pensar en un monismo tan lejano de la intención de Bergson. Su intuición, como afirma expresamente, no es identificación, sino contacto.

b) Significado irracionalista de la intuición. La teoría gnoseológica de Bergson es, parece ser, si no la más importante, sí al menos la más significativa del irracionalismo, que se podría llamar con toda razón contemporáneo... Y, por supuesto, es representativa del irracionalismo llamado intuicionista, modalidad del irracionalismo que hubiera quedado radicalmente lisiada sin la intuición de Bergson. Bien, la intuición bergsoniana, nace, como todo irracionalismo, de un juicio de disconformidad entre lo que conocemos y la capacidad cognoscitiva del entendimiento.

Llamamos irracional a lo que se encuentra fuera de nuestra categoría racional de cognoscibilidad. Cuando un objeto no es aprehensible racionalmente, se apellida irracional. Siendo este mismo apelativo el aplicado a nuestro conocer cuando éste se produce por un cauce distinto del entendimiento. Se trata, en uno y otro caso, de dos irracinalismos distintos que se podrían denominar convencionalmente óntico y gnoseológico respectivamente.

Pues bien, la intuición de Bergson lleva implícito ese doble irracionalismo. La intuición bergsoniana es el resultado de una doble hipótesis en su más estricto sentido etimológico: "la realidad última del ser es irracional". "Por otra parte, es un hecho que conocemos esa realidad con un conocimiento que necesariamente ha de ser irracional".

c) Crítica de la intuición bergsoniana. Se ha de enfocar esta crítica considerando su objeto desde un doble ángulo. En primer lugar desde el punto de vista de conclusión de un sistema. Evidentemente, tal como hasta ahora se ha expuesto, la necesidad del medio cognoscitivo irracional, parece evidente. Pero sólo lo es si se admiten como ciertos los postulados que hacen de la intuición una necesidad poco menos que humanista. El presupuesto de una sustancia que realmente no es sustancia y el par- 
cialismo con que Bergson ve y juzga el entendimiento, nos inducen a afirmarlo. Sí, Bergson prueba la intuición, pero la prueba poniéndola como conclusión necesaria de una teoría que es ella misma una intuición.

Queda, pues, por someter a juicio la intuición bergsoniana considerándola en sí misma. Y se ha de afirmar que nos parece humana, tal vez posible, desde luego probable y en muchos casos real. Pero no por eso nos da la impresión de ser científica. $Y$ esto se afirma primordialmente por la inexactitud de que el mismo autor la ha rodeado. La interpretación literal y exhaustiva de los párrafos en que el autor aporta datos sobre su intuición, desembocaría en conclusiones no pretendidas por él mismo. La intuición de Bergson no es sostenible desde un punto de vista científico de la filosofia.

El vitalismo, marco y gozne de toda la especulación bergsoniana es quizá, la explicación radical y completa de su teoría. $Y$ si al vitalismo añadimos el sano humanismo que empapa toda la obra de Bergson, comprenderemos, "intuiremos", la verdadera realidad y riqueza de la intuición bergsoniana. Apunta, pues, la línea de Bergson a liberar al hombre del nexo causal natural, pretendiendo una liberalización por medio de la intuición. En definitiva la gran solución ha de estar en una síntesis de racionalidad e irracionalidad de nuestro conocer.

\section{Bacon y su teoría de los idola.}

Como un claro antecedente de la Sociognoseología podemos fijarnos en Bacon, que trata de llevar a cabo un restablecimiento científico con base en la experimentación es decir, los montajes deductivos pretenden ser retirados del plano científico dejando paso a la inducción. Así pues, Bacon pretende restaurar la ciencia a base de la observación de los fenómenos naturales, sustituyendo el procedimiento deductivo por el inductivo, poniendo la base experimental en lugar de la silogística. Por consiguiente, la finalidad establecida por Bacon es la instauración del método experimental, empírico y positivo. ${ }^{4}$

En el Novum Organon, publicado en 1620, propuso una interpretación sociológica del conocimiento con la famosa teoría de los idola, considerados como falsas o defectuosas interpretaciones de la realidad y son de diferente procedencia.

-Unos provienen de la naturaleza del hombre o de la configuración psíquica y de la educación del individuo, son los de la tribu y la caverna.

-Otros tienen un origen típicamente social, los del mercado y del teatro. Que son los derivados de las relaciones mantenidas por los hombres entre sí, del uso del lenguaje y del peso que ejercen sobre el pensamiento humano teorías que han llegado a ser consideradas como tradicionales.

Así pues, la teoría de los ídolos dirige la atención hacia el origen de índole social del error, con lo cual queda anticipado uno de los temas capitales y que ocupará el centro de la sociognoseología, es el estudio de la ideología.

Hasta aquí se ha pretendido esencializar los diferentes ídolos, continuando con una

(4) Es de gran utilidad en esta línea el análisis de TUFARI: Sociología del Conocimiento. Vol. Cuestiones de sociología. Ed. Herder. 
valoración optimista de las posibilidades de reducir progresivamente los errores, tratando de hacer avanzar a la ciencia con el método inductivo. Y éste será, pues, el quehacer particular de hombres que Bacon describe en la visión utópica de The New Atlantis, estos hombres de ciencia, que se presentan como desembarazados de todo condicionamiento social y por ello capacitados para el establecimiento progresivo de un regnum hominis, esencialmente caracterizado por un dominio de orden eminentemente racional sobre la naturaleza y por un constante mejoramiento de las condiciones de vida.

También en esta última visión de índole utópica se encuentra anticipado otro de los grandes temas centrales de la Sociología del conocimiento, el de la existencia de grupos desclasados, por consiguiente no sujetos a condicionamientos, que han superado en totalidad.

Con todo ello se entrevee una concepción típica del conocer, considerado no como pura especulación sino como un posible camino o manera de control de la naturaleza, y de las condiciones de vida en provecho de categorías sociales más o menos extensas. Tenemos aquí superado en parte el clásico binomino sujeto-objeto, al que quedaba reducido en su totalidad el problema del conocer, no siendo ya, pues, el conocerimagen el que ocupe el máximo momento crítico.

Se está iniciando ya el pluralismo gnoseológico que en el futuro va a dominar a lo largo de la Gnoseología, considerando ya el conocimiento como algo perteneciente a la actividad vital del hombre, como una manifestación de su existencia, no pudiéndose analizar el conocer de una forma imparcial.

\section{Planteamiento de Saint-Simon}

Toda su línea de pensamiento puede ser considerada de una fecundidad suma, dado que sirve de soporte, tanto al planteamiento positivista de Compte, como a la filosofía social del XIX. Y ambas directrices, positivismo y socialismo, son dos verdaderos ejes centrales de la Sociología del conocimiento.

Tengamos en cuenta que la Sociología del conocimiento, aún en su intención de considerarse ciencia positiva en pureza, no obstante se presenta totalmente transida de filosofia, pues toda su enorme problemática se plantea según problemas estrictamente filosóficos, así por ejemplo, la cuestión relativismo, objetividad...

Toda la gran problemática apuntada en todos los análisis realizados hasta hoy, y teniendo en cuenta su base positiva, es la posibilidad de considerar la sociognoseología como ciencia socio-positiva o como gnoseología. Problema en el que más adelante trataremos de adentrarnos.

Concentrándonos de nuevo en la raiz socio-positiva de la Sociología del Conocimiento, se aprecia como permanece en Saint-Simon una tesis, según la cual, todo análisis social de grupo humano se realiza en el punto coincidente de dos cordenadas, por un lado su vertiente ideológica y por otro las instituciones sociales. Y así, pues, los diferentes modos de planificación social de grupos tienen sus características formas de conocer, por ejemplo, al régimen militar le corresponde un conocer técnico. En este sentido hay una bipolaridad muy relacionada, en el establecimiento realizado por Saint- 
Simon, entre progreso material y progreso cognoscitivo, pero no afirmando la primacía del nivel cognoscitivo sobre el material.

$Y$ es por todo ello, por lo que en alguna de sus obras (La science de l'homme y Le Catechisme des industrieles) pone de relieve la suma importancia del progreso material, acentuando la gran relevancia del proceso de industrialización, no sólo en orden a un mejoramiento de tipo externo de la vida, sino de índole también interna en toda la transformación comunitaria e individual.

No siendo la dimensión individual la que polarice su atención sino más bien su ideal de solidaridad social, la cual ha de ir apoyada en un fuerte principio autoritario.

Como apéndice de este punto, se puede apreciar, no obstante que a pesar de ser considerado Saint-Simon como la raiz del socio-positivismo posterior, fundamento de la Sociología del conocimiento, sin embargo, podemos considerar a Durkheim como uno de los más fidedignos exponentes de la tendencia a la filosofía positiva, iniciada ya por Compte.

Todo el punto de máxima atención, por parte de Durkheim, se centra en la cuestión de la solidaridad social, es decir, los puntos por los que grupo e individuo se presentan interdependientes, examinando fundamentalmente la relación existente entre plano cognoscitivo y estructura social, punto que ocupa todo el eje medular de la futura Sociología del conocimiento. Según Durkheim, todo proceso cognoscitivo sufre un condicionamiento social, llegando al siguiente planteamiento, no es el conocer el eje fundante sociológico, sino que son las vertientes sociales los fundamentos de donde surge el conocer en sus diferentes manifestaciones, siendo la experiencia social el origen de los niveles categoriales lógicos y de los juicios de valor.

Según esto, se puede apreciar cómo quedan abiertas ya las puertas al relativismo cultural, en cuanto que el conocimiento queda reducido a función social, dado que el conocimiento no es más que la expresión de un grupo social, con lo cual cada grupo tendrá su conocimiento. Punto que nos va a surgir de nuevo en el estudio de la Sociognoseología, en uno de sus puntos más criticables y debatidos el del relativismo. Pues, según este establecimiento va a ser la colectividad quien en definitiva surja como criterio garante de la validez del conocer. Posteriormente, al igual que Mannheim, aunque por diferentes caminos, va a intentar superar ese relativismo, lógico resultado una vez establecidos sus fundamentos.

\section{K. Marx y la ideología}

a) Exposición del relativismo pragmatista. Toda la base del pragmatismo respecto de la verdad está en que la verdad es constituída en sí por la utilidad. Vemos que, esta utilidad, como base del criterio de verdad, no es satisfactoria, ya que ni los mismos pragmatistas convienen en definir la utilidad; es indefinible pues verdades que ahora pueden ser útiles, luego pueden resultar inútiles. La raiz de donde nace toda esta corriente, es una reacción contra el intelectualismo existente, viendo que el conocimiento entendido en un sentido real es gratuito, por tanto la verdad es indefinible, no queda más verdad que aquella que venga hecha vida, es decir, que me agrade, que me sea útil por tanto, toda verdad que venga por intellectus no me sirve para nada. 
Si nacen como reacción contra el intelectualismo, su doctrina ha de ser empirista, admitiendo evolución en el conocimiento. Ahora bien, el pragmatismo si no admite algunas verdades absolutas caerá en el escepticismo puro, no obstante parece ser que el relativismo conoce algo absolutamente, a saber, que mi conocimiento es relativo.

El conocimiento en el pragmatismo es puro instrumento para la acción ya que el conocimiento es alguna función de la vida y no está ordenado a la contemplación sino a la acción, luego tiende a perfeccionar la vida acomodando al sujeto viviente el medio ambiente.

Además pára el pragmatismo, en tanto una cosa es verdadera en cuanto supone alguna satisfacción para el que conoce, por ello la razón de la verdad es la utilidad del conocimiento, la verdad es relativa. Luego no tenemos una categoría de verdad sino de bien, por lo que el criterio de verdad queda en la utilidad.

Por consiguiente, podemos ver que el pragmatismo no es una doctrina filosófica sino que es un método para evitar los problemas especulativos, es antidogmático, ninguna verdad es fija.

b) Esquema gnoseológico. La tesis fundamental es la identidad de realismo y materialismo. Afirma Lenin: "La tesis fundamental es la existencia de una cosa reflejada especularmente independiente del reflejante (la independencia del mundo externo respecto a la conciencia).

Según Engels, la relación pensar-ser o espíritu-naturaleza, dividía a los filósofos, los que afirman la prioridad del espiritu son idealistas, y los que afirman la prioridad de la naturaleza son materialistas, no hay término medio. Lenin afirma: "De la intuición viva al pensar abstracto y de éste a la praxis, tal es el camino dialéctico para el conocimiento de la verdad", es decir, la praxis es la que ha de garantizar la concordia del pensar con el ser.

Respecto del conocimiento sensible, su origen lo podemos ver en la excitación de las cosas exteriores en nuestros órganos sensoriales. Y afirma Lenin: "es la transformación de la energía de los excitantes externos en un hecho consciente".

Sobre el sustrato del conocimiento sensitivo, la distinción entre sensación consciente y proceso fisiológico es relativa. La materia es capaz de conciencia, pero la materia organizada con especial delicadeza. Afirma Lenin, conciencia es el más elevado producto de la materia, una función de aquel trozo de materia especialmente complicado llamado cerebro humano.

Ahora bien, el atribuir conciencia a toda materia es ilógico, según Pearson, pero es lógico admitir que toda materia tiene una propiedad que es esencialmente afín a la sensación, y esta propiedad de la imagen especular. La sensación será entonces una imagen especular de la realidad que por lo menos en el hombre se hace consciente.

Hemos de considerar la praxis como criterio de verdad. La cuestión es la siguiente: ¿Cómo sabemos si nuestros sentidos nos dan la verdadera imagen de las cosas percibidas por ellos? Sabemos si la imagen es exacta, cuando podemos obrar a partir de dicha imagen, cuando nuestra acción tiene éxito o no. Pero podemos preguntarnos qué es la praxis, es el trabajo humano productivo de bienes, praxis social. Hay una diferencia contra este criterio, que toda idea asentada en asertos a priori y valederos independiente de la experiencia queda rechazada como idealista. 
Para el materialismo el pensar está unido esencialmente al cerebro humano. La praxis social o trabajo social no sólo es el criterio de verdad sino el fundamento del proceso cognoscitivo.

¿Cómo queda pues en este esquema la abstracción? El conocimiento sensible nos da imágenes de los objetos reales sensibles, su conexión externa, pero no puede penetrar en la esencia de lo fenómenos sin ayuda del pensar abstracto, ni descubrir en las cosas sus conexiones internas, ni descubrir la ley de su existencia y de su evolución o desarrollo.

Hay muchas teorías para explicar el proceso de la abstracción, y casi todas ellas llegan a que se presenta como la imagen especular de lo general esencial.

En consecuencia, el materialismo dialéctico, niega la metafísica tanto como dirección filosófica que trabaja con categorías fijas, como doctrina que va más allá de la experiencia. En lo que respecta a lo primero, vemos que la rechazan en cuanto que se opone a la Dialéctica apoyada en categorías fluentes. Y para lo segundo, también la rechazan puesto que extenderse más allá del espacio y tiempo es en concreto para algunos un contrasentido medieval.

Además parece que no se admiten verdades absolutas, pues si nosotros nos acercamos a la verdad absoluta, sólo se nos puede dar en nuestro juicio, la verdad absoluta entonces todavía no existe.

Por otro lado parece que el materialismo dialéctivo renuncia en parte al relativismo, una variedad de relativismo es el pragmatismo, y pudiera parecer como si el materialismo dialéctico se acercara a él con su criterio de la praxis, pero hay distinción. En el marxismo el juicio verdadero es un instrumento de la acción y por eso útil. Por el contrario en el pragmatismo la relación está invertida: el juicio no es útil porque es verdadero sino que es verdadero porque es útil.

A pesar de todo, parece que en el materialismo dialéctico se contiene una parte esencial de pragmatismo y relativismo, es la doctrina llamada de las ideologías. En el materialismo se rechaza toda Metafísica y toda doctrina religiosa, pero no puede negarse que tienen sumo influjo en la historia de la humanidad estas convicciones, pero ¿de donde vienen?, según el materialismo no pueden probarse lógicamente, luego sólo se podrá dar una explicación psicológica o histórica, con lo que se hacen del todo relativistas.

c) Planteamiento marxista de las ideologías En toda esta línea suya, su teoría de la ideología es considerada como el paso inmediatamente anterior a la Sociología del conocimiento, mediante la cual establece los influjos de tipo económico-político en el ámbito cognoscitivo, llegando al establecimiento de una correspondencia entre elaboraciones mentales y estructuras sociales. Según afirma explícitamente Marx: "No es la conciencia de los hombres la que determina su existencia sino al contrario, su existencia social determina su conciencia", "la infraestructura económica determina la superestructura lógica".

En definitiva, todo este planteamiento se puede considerar como las conclusiones

(5) Tesis presentadas fundamentalmente en Die deutzche Ideologie y Zur Kritik der Politischen Oekonomie. 
prácticas sacadas por Marx de la filosofía de Hegel considerada como continuación de la gran aportación kantiana en la consideración pasivista del conocer.

Se puede afirmar que la dependecia del conocer ideológico respecto de la infraestructura económica, no puede considerarse en un sentido de pura univocidad, dado que existe el más y el menos en esta dependencia, es decir, aunque todo conocer ideológico está condicionado por la infraestructura económica, sin embargo no lo está de la misma manera en todos los casos. Se ha de aclarar que los elementos constitutivos de la base estructural económica, son tanto las fuerzas de producción, como el conocer técnico y científico y todo ello es la base fundante y condicionante del conocer ideológico.

Ahora bien, si el conocer técnico-científico no puede considerarse como superestructura sino como nivel infraestructural podemos preguntar ¿cuál es el conocer que queda englobado en la superestructura? se trata del conocer religioso, político, filosófico, etc., siendo fundamentalmente en el conocer político donde se aprecia ese condicionamiento de la infraestructura económica de una forma más patente.

El punto que parece presentar mayor dificultad, es la determinación de la correspondencia existente entre infraestructura y superestructura, pues se está de acuerdo en la existencia siempre de ésta interrelación, la diferencia llega a la hora de determinar el grado de influjo de la infraestructura en la superestructura. Pues a veces dicha relación se ha entendido de una forma directa e inmediata, siendo por ello la superestructura una mera manifestación o explicitación de la base económica sin ningún tipo de autonomía; sin embargo, otras veces dicha relación se ha concebido como influjo mediato, quedando salvada en parte una cierta autonomía en la vertiente estructural.

\section{d) Correlación Marx-Mannheim}

No hay duda, y todos coinciden en seffalar a Marx como el inmediato predecesor . de la Sociología del conocimiento, por ello, sin perder esto de vista, vamos a repasar aquellos puntos concretos por los que se aprecia la correspondencia clara entre Marx y Mannheim, no sin anotar aquellos rasgos en los que Mannheim explícitamente se manifiesta en desacuerdo.

Son varios los autores de inspiración marxista, aunque algunos invirtieron el planteamiento, poniendo por base los niveles ideológicos antes que los infraestructurales económicos. Tenemos a Lukacs, cuyo gran problema es la relación ideología y clase, tratando de establecer en primer lugar los rasgos esencializantes de una ideología para determinar posteriormente la clase de su verificación. Marx Adler, analizando los niveles categoriales de Kant, le critica su desconocimiento de una categoría fundamental en el conocer, la social. Posteriormente Bauer, etc.

Centándonos en Mannheim, como uno de los pilares fundamentales sobre los que se asienta la Sociognoseología estructurada, veamos sus dependencias con respecto a Marx y sus puntos de diferenciación.

Existe un punto fundamental, Schaff lo anota explícitamente, de estricta dependencia de la Sociognoseología con respecto al maxismo, es la teoría marxista de la base y la superestructura: "Así pues, esta cuestión que constituye la esencia y la originalidad de la sociología del conocimiento ha sido recogida claramente del marxismo. De la 
misma forma, además que el interés que presta a esa parte específica de la superestructura que es la ideología".

Antes de examinar cómo Mannheim ha aplicado e interpretado la teoría marxista de la base y la superestructura así como la de la ideología, yo quisiera subrayar que el vínculo genético de la sociología del conocimiento con el marxismo ya la deuda intelectual que aquella contrajo con éste es mucho más profunda, se refiere a los elementos fundamentales de la doctrina de Mannheim, aunque no siempre se hayan puesto en claro ni hayan sido destacados". 6 "No es la conciencia quien determina la existencia social sino, por el contrario, la existencia social quien determina la conciencia social, afirma Marx y Engels. Utilizando la posibilidad que ofrece la lengua alemana, expresan este pensamiento en la Ideología alemana bajo una forma que recuerda el retruécano: "Das Bewisstseii kann nie etwas anders sein als des bewussite Sein" (la conciencia no puede ser otra cosa que la existencia consciente).

Las relaciones entre la ciencia sccial y la existencia social no conllevan el carácter de una dependencia de causa a efecto unilateral. La correspondencia, de Engels, hacia el término de su vida, lo precisa claramente. Son presentadas por los autores de la teoría por medio de imágenes como relaciones entre la base y la superestructura. Si no es más que una imagen, ésta no obstante sorprende la imaginación al punto que ha creado dificultades teóricas por haber sido comprendida demasiado al pie de la letra. Más tarde, Engels tuvo que hacer a este propósito un cierto número de aclaraciones polémicas.

La existencia social es llamada "base", sobre la cual y según la cual —“en última instancia", como dice prudentemente Engels a continuación teniendo en cuenta la dependencia y las influencias mutuas que intervienen entre ellas - se levanta la "superestructura" edificio complicado de ideas y de actividades humanas sobre la realidad, así como de instituciones que le corresponden. La "base" o dicho de otra manera, la "existencia social" es - según los creadores de la teoría del materialismo histórico- una estructura complicada de objetos y relaciones humanas"?

No obstante Mannehim no admite en su totalidad el establecimiento marxista de considerar la superestructura sólo como producto de la infraestructura, parece ser, según Mannheim, que existe algo más "Es una completa aberración ver en la Cultura sólo un fenómeno reflejo de las estructuras económicas. Aún cuando las conexiones económicas fuesen la "variable independiente" en el proceso de la Historia y quisiéramos ver en ellas el origen de todas las formas te la integración social y división de funciones (lo que no hemos de discutir aqui), aún entonces quedaría como tarea especial la de investigar cómo operan en los distintos terrenos de la actividad humana esas formas de socialización, estimuladas por la economía".

Continuando en esta misma línea, Mannheim admite la influencia infraestructural económica en la vertiente cultural, pero hay algo más que no es reductible pura y simplemente a la Economía, es decir la cultura es economía y algo más, pues en general Economía y Política cimentan la sociedad pero tan sólo parcialmente, pues hay

(6) SCHAFF, A. Sociologla e Ideologia. A. Redondo Editor. Barcelona, 1971, pág. 46.

(7) SCHAFF, A. O.C. pág. 74.

(8) MANNHEIM, K. Hombre y sociedad en la époce de crisis. Ed. Leviatán. Buenos Aires, pág. 15. 
algo más en profundidad que dictamina la orientación de índole sociológica: "La Sociedad está involucrada en la Cultura misma y la conforma en cada instante. Por eso, es falso atribuir a la sociedad (cimiento) sólo la Economía y la Política, y hablar de Sociología de la Cultura en el sentido tan sólo de ver cómo esas esferas actuan sobre la cultura.

En lo que sigue nos proponemos justificar la tesis enunciada en los comienzos, de que las mismas tensiones que en la Economia producen su desdicha, funcionan también en lo cultural. Correspondiendo a los dos grandes principios contradictorios del laissezfaire liberal y de la regulación, nuestra cultura está amenazada desde dos lados: está expuesta a peligros ciertos, estrictamente computables, en tanto que la sociedad democrática de masas se encuentra abandonada a sí misma a peligros mucho mayores, aún cuando en esa sociedad de masas las formas dictatoriales desplazan a las liberales. A estas dos afirmaciones hay que afiadir una tercera, a saber, que las mismas causas sociológicas que producen la descomposición cultural en la sociedad liberal son las que preparan el camino para las formas dictatoriales.

Estas tres afirmaciones, colocadas en la cúspide, sólo adquieren valor científico y significación práctica para el político de la Cultura cuando no sólo hablamos en general de peligros y decadencia de la Cultura como por ejemplo, ha hecho Spengler sino que se muestran en particular y se colocan en situación de analizarlas aquellas fuerzas sociales y series de causas que producen la descomposición de la Cultura".

No obstante existen puntos claros, que Mannheim ha adoptado de la estructuración marxista, así la relación existente entre el conocimiento y su marco social, es decir, el análisis del proceso cognoscitivo ha de llevarse a cabo no a partir del individuo aislado sino socialmente considerado, dentro de cuyo marco actúa. Según anota Schaff, Mannehim toma este punto del marxismo: "El análisis del proceso del conocimiento debería partir pues, no del individuo autónomo desprendido de la sociedad y opuesto a ella, sino por el contrario, del grupo social en cuyo marco actúa el individuo, con el cual coopera y al que da su forma. Este desplazamiento del acento desde el individuo, comprendido como autónomo, al grupo social y en consecuencia al individuo comprendido socialmente reviste una importancia decisiva para la Sociología del conocimiento. Solamente en este terreno, que él ha tomado al marxismo, Mannheim puede expresar la tesis que constituye la base de su razonamiento ulterior sobre la determinación social del conocimiento humano". ${ }^{10}$

Otro punto anotado por Schaff, establece una nueva relación de dependencia de la Sociología del conocimiento con respecto al marxismo, se trata de la manera común de abordar el proceso del conocimiento, considerando el conocer no como una mera función intelectual-abstracta sino que se ha de soportar en la acción colectiva. Además al considerar el conocer eminentemente como función vital, carece de sentido el observarlo como algo meramente estático: "En fin hay otro elemento que liga la Sociología del conocimiento con el marxismo y sobre el cual yo quisiera llamar la atención particularmente al principio de nuestro análisis, se trata de la manera en que Mannheim aborda el proceso del conocimiento.

(9) MANNHEIM, K. O.C. pág. 66-67.

(10) SCHAFF, A. Sociología e ideologia. pág. 47. 
En primer lugar, y siguiendo de forma neta las trazas de Marx, Mannheim subraya que el conocimiento no es un acto abstracto y teórico, sino que se apoya en la acción colectiva.

En segundo lugar, y aquí también el lazo estrecho con el marxismo aparece claramente, Mannheim considera que se debe abordar el conocimiento de forma dinámica, en cuanto proceso, y no de manera estática. Esta es una tesis extremadamente importante para la solución de los problemas que se derivan de la sociología del conocimiento". 11

Una de las ideas más fundamentales, como vimos anteriormente, del materialismo histórico es la relación establecida entre el conocer y su determinación social, a todo este problema se orienta la cuestión de base y superestructura, centrándose en el condicionamiento situacional sufrido por la ideología. Punto éste que va a tener suma trascendencia en el planteamiento sociognoseológico establecico por Mannheim: "La idea fundamental del materialismo histórico que ya hemos recordado, es la tesis sobre la determinación social de la conciencia humana. A este problema está consagrada la teoría de la base y de la superestructura particularmente cualificada, al indicar el vínculo de toda ideología con la situación, las aspiraciones y los intereses de grupos sociales determinados, el marxismo ha inspirado a Mannheim el desarrollo de la teoría de la ideología. Este vínculo genético es indudable (el mismo Mannheim habla de él) incluso si, radicalizando la concepción de Marx se ha separado de ella en realidad.

Poniendo todas las ideologías sobre el mismo plano, Mannheim no puede liberarse de su relativismo. ${ }^{12}$

Es necesario puntualizar la distinción que establece Mannheim entre ideología total y particular, pues en la concepción particular sólo una parte de las opiniones son juzgadas como falsa conciencia, mientras que para las totales, el conjunto de concepciones es juzgado como falsa conciencia: "Lo que hace diferir, según Mannheim, las dos concepciones de la ideología es, en primer lugar, el hecho que en la concepción particular de la ideología, sólo una parte de las opiniones de adversario es juzgada como una falsa conciencia y funcionaliza únicamente el lado psicológico, conservando la base de conocimiento (noológico) común a los dos interlocutores, en tanto que para la concepción total de la ideología, el conjunto de concepciones del oponente, con su aparato conceptual es juzgado como una falsa conciencia" ${ }^{13}$ No obstante el punto que le interesa y del que se ocupa la Sociognoseología es la concepción total de ideología, centrándose fundamentalmente en el plano cognoscitivo cambiante.

e) Su postura final Ya en su última fase, Mannheim da un cambio bastante notable en su línea de pensamiento, llegando a afirmar la existencia de unos valores -aunque sin determinar cuales - como permanentes, y asignando a la religión el papel de quedar convertida en la definitiva integración de valores. No se trata por ello de una permanencia axiológica estática sino esencializante, es decir, existe un cuerpo valorativo permanente que necesita históricamente irse acomodando a las circunstancias del

(11) SCHAFF, A. 0.C. págs. 47-48.

(12) SCHAFF, A. O.C. págs. 48-49.

(13) SCHAFF, A. O.C. pág. 50. 
momento actual, temporal.

Así pues, Mannheim no ha anulado de forma total y absoluta, todo tipo de condicionamiento, pues la persona en tanto lo es, en cuanto aparece condicionada socialmente, presentando unos rasgos diferenciadores, es decir, una personalidad feudal es diferente de una personalidad renacentista, en cuanto ha existido un medio ambiente distinto que las ha caracterizado: "Además, la estructura de una personalidad bien integrada corresponde a la fuerza condicionadora de dicha sociedad, ya a la personalidad ideal a la que trata de conformarse el individuo. Las condiciones ambientales materiales e ideales- determinan las aspiraciones y los motivos de los individuos, sus reacciones personales, por ejemplo, e influyen los principios que sirven de guía para su conducta. Al mismo tiempo, como ya hemos visto, dan forma al tipo de conciencia evolutiva, de la misma manera que, en último término, afectan al desarrollo de la personalidad. Después debemos también comprender que las normas del desarrollo de la personalidad debido a su carácter socialmente condicionado, varían según los distintos periodos históricos. Las estructuras de la personalidad que dominaban en la sociedad feudal, por ejemplo, difieren de las del Renacimiento; y los tipos sociales que prevalecen en la sociedad inglesa actual, difieren de los que fueran moldeados por el sistema soviético o por el sistema nazi en Alemania". ${ }^{14}$

Por consiguiente, se puede afirmar que la sociedad contornea nuestra personalidad, es decir, la va impregnando de ciertas características dándole una cierta unidad por la que se define históricamente. Pero la gran novedad radica, según Mannheim, en que ahora somos conscientes de nuestro condicionamiento por tales procesos, y es por ello por lo que estamos con posibilidad de controlarlos: "No es este el lugar adecuado para discutir de qué manera la sociedad, además de dar forma a ciertas características de nuestra personalidad, consigue influir la variedad de estructuras a partir de las cuales surge en la personalidad humana cierta unidad y consistencia. Más tarde podremos demostrar que el Yo se desarrolla gracias a formas de interacción, y a los papeles que se le permite desempeñar en un orden social dado. Al influir la naturaleza de estos tipos de interacción, al dar nueva forma a los papeles sociales que el individuo ha de desempeñar podremos cambiar a las personas en grado considerable. Esta educación en los individuos mediante la asignación de papeles no es nada nuevo, pues el proceso de la historia ha trabajado siempre mediante tales sistemas. La única novedad consistente en que ahora somos conscientes de tales procesos, y así podremos controlarlos con mayor lucidez". 15

De todo el problema del condicionamiento social de la personalidad hablar Marx al tratar lo que él denomina "máscaras del carácter", produciéndose en infinidad de individuos un acondicionamiento social, lo cual llevaba implicados unos trastomos generales en la personaliđad. Según examina Mannheim, Marx tomó conciencia de que parte de la conducta se encuentra influenciada por segmentos de la realidad, pero ni Marx ni sus seguidores explican toda la estructura del carácter, desde la vertiente condicionante: "El concepto marxista de la "máscara del carácter". Existen muchos ambientalistas, pero la mayor parte de ellos no van más allá de lo que hemos llamado con-

(14) MANNHEIM, K. Libertad, poder y planificación democrática. pág. 248.

(15) MANNHEIM, K. O.C. pág. 249. 
dicionamiento "segmental". Admiten que cierta parte de la conducta está influenciada por segmentos de la realidad, pero no explican toda la estructura del carácter, en términos del condicionamiento social, ni indican cómo se imprime en la mente humana el hecho de que ésta es un producto social. Aqui Marx estaba en lo cierto cuando habló de las "máscaras del carácter" que cubren la verdadera naturaleza humana. Marx planteó el problema del divorcio entre el hombre y su verdadera naturaleza, como consecuencia de la degeneración de las relaciones humanas, puesto que únicamente por obra y gracia de estas relaciones desarrolla o reprime el hombre sus posibilidades. Sin duda preveía muchas intuiciones modernas en los campos de la antropología, la sociología y la criminología, al decir que los desadaptados sociales se desarrollan como resultado del acondicionamiento ambiental" ${ }^{16}$

Posteriormente, y además del tema de las "máscaras del carácter" trae Mannheim a colación otra cita de Marx respecto del problema de la autoalienación, según lo cual Marx afirma que el dinero más que meramente un medio, es el verdadero poder y único fin, veamos la cita propuesta por Mannheim: "El dinero, que parece ser meramente un medio, es el verdadero poder y único fin. El medio que me trasforma en un mero sujeto, que me permite apropiarme de las cualidades materiales de otros, es un fín en sí mismo. Esto es cierto, en verdad, tal como podemos ver en el reconocimiento de la propiedad territorial, en tanto que verdadero poder político de la vida, alli donde la tierra es la fuente de vida, y del caballo y la espada, alli donde éstos son los verdaderos medios de existencia. En la Edad Media, un estamento se emancipa en cuanto sus miembros tienen privilegio para llevar espada. Entre los pueblos nómadas es el caballo el que hace libre al hombre y lo convierte en miembro de la comunidad... Sea lo que fuere lo que yo pueda comprar, lo que pueda pagar con dinero, lo que pueda pasar a ser mío gracias al dinero, esto es mi Yo soy yo, como propietario del dinero". ${ }^{17}$

Veamos ahora cual es la postura al respecto de Mannheim, cómo no está en todo de acuerdo con Marx, sobre todo en la parte referente a los influjos condicionantes de la economía, considerándola no como la única sino como una de las muchas fuerzas que condicionan los diferentes estamentos sociales: "Pero, según mi opinión, no hay razón para suponer que la sociedad feudal, por ejemplo, haya producido menos autoalienación, o que en las sociedades primitivas el hombre haya sido más auténtico. Existen muchos otros problemas inherentes a la idea del hombre además de las máscaras y de la autoalienación. Incluso sin embarcarnos en el problema de la verdadera naturaleza del hombre, excluyendo su realización histórica, podemos decir que las sociedades primitivas, con sus costumbres y hábitos fijos, parecen una camisa de fuerza, si las comparamos con las sociedades más elásticas que han creado las técnicas económicas y sociales, y que al menos ofrecen soluciones alternativas a nuestros problemas. Esta mayor elasticidad de la organización moderna es en sí un progreso hacia la autorrealización, aún si debemos admitir los efectos polarizadores de un sistema social basado en lo que Carlyle llamaba, "El nexo del dinero líquido".18

No obstante, Mannheim, sabe apreciar lo positivo de la línea general del plan-

(16) MANNHEIM, K. O.C. pág. 256.

(17) MANNHEIM, K. O.C. págs. 257-258.

(18) MANNHEIM, K. O.C. pág. 258. 
teamiento de Marx, en lo referente a la relación establecida entre individuo y sociedad, en cuanto que es la sociedad la que queda constituída en el soporte estabilizador del individuo, Mannheim habla explícitamente de la "preexistencia temporal y lógica del proceso social frente al individuo conscinete de sí mismo que en él surge".

Como conclusión de este apartado es de sumo interés hacer referencia a la distinción que Mannheim establece entre el Yo y el Mi, examinando cómo hay algo en la profundidad de la persona no sometido al ámbito situacional, precisamente donde podríamos plantear el problema de la libertad, siendo precisamente el Mi, la máscara social, que adquirimos gracias al papel social que hemos de desempeñar: "La convicción de que todos los papeles que desempeñamos y todas las máscaras que usamos, no agotan la personalidad, sino que hay una persona detrás de los papeles sociales y de las máscaras, es una base común de todas las filosofias de la libertad. En el nivel religioso, este espiritu es concebido como entidad metafísica, innata en el individuo desde que éste empieza a vivir. Es un núcleo que en alguna forma no es afectado por la causación, que no toca más que la superficie de la existencia humana. En las filosofías más empíricas del positivismo y el pragmatismo, este núcleo dinámico del yo no es preexistente, pero va surgiendo gradualmente del proceso social como un "yo". Este yo se opone al mi, que es la máscara social a que nos hemos referido, y que adquirimos gracias al papel social que hemos de desempeñar. El yo, según la expresión de William James y G.H. Mead, es la parte dinámica del uno mismo que en todas sus reacciones contra el desafío que le plantea la situación social no puede ser predicho. Nuestros diferentes mis son, por decirlo asi, las improntas masivas de todas las influencias a las que estamos expuestos cuando desempeñamos nuestros respectivos papeles sociales por ejemplo, como padre, como hombre de negocios, respondemos a lo que se espera, y estas desviaciones se transforman en la fuente de la singularidad y de la infinita variación".19

(19) MANNHEIM, K. O.C. pág. 261. 